\title{
EL PLURALISMO ACADÉMICO
}

\section{ACADEMIC PLURALISM}

Ddgar Gutiérrez Gómez ${ }^{1 *}$

egutierrez@unah.edu.pe

${ }^{1}$ Universidad Nacional Autónoma de Huanta, Ayacucho, Perú

*Correspondencia: Edgar Gutiérrez Gómez. Email: egutierrez@unah.edu.pe

Las universidades a nivel mundial se erigieron en una comunidad de académicos y docentes, pasando etapas de su proceso histórico, fueron acomendándose a las circunstancias del contexto histórico. El origen de universitas "totalidad" derivado del universum, "reunido en un todo" paulatinamente hicieron un viraje académico al pluralismo, descartando el elitismo con mayor acceso al público que busca la universidad de su interés. La Reforma Universitaria de Córdoba realimentó el pluralismo académico en Latinoamérica, como se indica: "Nació entre nosotros una universidad mixta, con institutos de ciencias y escuelas profesionales, dotadas estas últimas también de centros de investigación" (Chuaqui, 2002, págs. 563-565) es así, actualmente las universidades tienen la misión de implementar sus institutos de investigación con productos científicos de calidad de componente multidisciplinar. A esta consideración científica, publicamos nuestro segundo número de revista PURIQ respetando el pluralismo académico de sus autores que cumplieron en presentar sus artículos de su interés.

El contexto actual del mundo académico, necesita otros escenarios para estar en condiciones de competir con la digitalización de libros, artículos científicos, ensayos y la información en tiempo real. "Más de una década después de su fundación, los gigantes de las redes (Facebook, YouTube, Twitter, Google) han comenzado a entender que su enorme poder como filtros de contenido para el mundo entero implica una responsabilidad editorial" (Galindo, 2018) Por este cuidado, nuestra editorial respeta el pluralismo del pensamiento de sus autores, exponiendo a sus lectores activos y potenciales a tener una lectura multidisciplinar. Tenemos el propósito de superar la valla establecida en el primer número: "Los artículos seleccionados para este primer número son de absoluta responsabilidad de sus autores, quiénes voluntariamente cumplieron con los requisitos establecidos en su convocatoria para su publicación, además dejan a un escrutinio de la comunidad científica el producto de su investigación" (Gutiérrez, 2019, p.7) La publicación que contiene este volumen, fue puesto en I consideración científica por el equipo editorial y comité científico que apoya la publicación; al mismo tiempo, está refrendado con sello de calidad de los evaluadores ciegos que participan de manera voluntaria en la publicación del presente número.

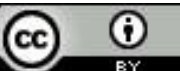

\section{REFERENCIAS BIBLIOGRÁFICAS}

Chuaqui, B. (2002). Acerca de la historia de las universidades. Revista chilena de pediatría, 6(73), 563-565.

Galindo, J. (16 de 08 de 2018). El precio del pluralismo. El País. Obtenido de https://elpais.com/elpais/2018/08/15/opinion/1534335278_187230.html 
Gutiérrez, G. E. (2019, p.7). Editorial. Puriq, 01, 07. doi: https://doi.org/10.37073/puriq.1.01.53

\section{CITAR COMO:}

Gutiérrez Gómez, E. (2019). El pluralismo académico. Puriq, 1(02), 118-119. https://doi.org/10.37073/puriq.1.02.51 